\title{
Utilização dos testes de mutagenicidade para a avaliação de exposição ocupacional
}

\author{
Use of mutagenicity tests to assess \\ occupational exposure
}

\author{
Ana Gabriela da Silva Kohatsu', Fernanda Shimabukuro², \\ Gilka Jorge Fígaro Gattás ${ }^{3}$
}

\begin{abstract}
Kohatsu AGS, Shimabukuro F, Gattás GJF. Utilização dos testes de mutagenicidade para a avaliação de exposição ocupacional. Saúde, Ética \& Justiça. 2007;12(1/2):15-21.

RESUMO: Os testes citogenéticos para avaliação de mutagenicidade são importantes biomarcadores de exposição, pois correspondem à expressão de um agente ambiental e seus metabólitos no meio intracelular. Por isso, vêm sendo utilizados no monitoramento biológico de populações expostas a substâncias genotóxicas. Em trabalho realizado com 24 motoristas de ônibus da cidade de São Paulo, utilizando-se o teste do micronúcleo observou-se uma freqüência de células anormais maior, que a encontrada no grupo considerado como controle, de 13 motoristas de ônibus afastados da função. Apesar do número reduzido de indivíduos, os resultados parciais dessa pesquisa, realizada com pacientes em atendimento no Serviço de Saúde Ocupacional do HCFMUSP, sugerem a ampliação desse projeto para avaliação da possível inclusão de protocolos de acompanhamento periódico desses profissionais.
\end{abstract}

DESCRITORES: Citogenética. Testes de mutagenicidade. Testes para micronúcleos. Exposição ocupacional. Saúde do trabalhador. Motorista de ônibus.

\section{INTRODUÇÃO}

A Genética Toxicológica é uma área de atuação multidisciplinar que envolve geneticistas, toxicologistas, médicos e biologistas moleculares entre outros, com o objetivo de detectar e entender a ação de substâncias genotóxicas sobre o organismo. Esta especialidade da genética avalia as agressões que o DNA e os sistemas reguladores celulares sofrem, bem como as estratégias para se defender ou corrigir as falhas ocasionadas.

O DNA é uma molécula extremamente estável que pode ter sua seqüência de pares de bases alterada após um único ciclo de replicação com incorporação errônea de um nucleotídeo não reparado (alteração

1 Bióloga, Aprimoranda em Saúde e Trabalho pelo Serviço de Saúde Ocupacional do Hospital das Clínicas da Faculdade de Medicina da USP.

2 Biomédica, Mestranda de Fisiopatologia Experimental - Departamento de Medicina Legal, Ética Médica e Medicina Social e do Trabalho da FMUSP - Laboratório de Imunohematologia e Hematologia Forense (LIM/40).

3 Professora Associada do Departamento de Medicina Legal, Ética Médica e Medicina Social e do Trabalho da FMUSP.

Endereço para correspondência: Profa. Dra. Gilka J. F. Gattás, Departamento de Medicina Legal, Ética Médica e Medicina Social e do Trabalho - Instituto Oscar Freire Faculdade de Medicina da Universidade de São Paulo. Rua Teodoro Sampaio, 115. CEP: 05405-000. São Paulo, SP. e-mail: gfgattas@usp.br 
Kohatsu AGS et al. Utilização dos testes de mutagenicidade para a avaliação de exposição ocupacional.

espontânea), ou sofrer mecanismo semelhante induzido por agentes físico-químicos (alteração induzida). Essas alterações, definidas como mutações, se não sofrerem reparo antes do próximo ciclo celular, poderão ser fixadas e constituir mudanças herdáveis. Além das mutações pontuais, os rearranjos cromossômicos, por gerarem pareamentos desiguais, podem alterar de forma drástica a seqüência original do DNA.

As mutações podem ser classificadas em "gênicas" ou "de ponto", quando envolvem uma ou mais bases púricas ou pirimídicas do nucleotídeo e "cromossômicas", quando envolvem modificações na estrutura e/ou no número de cromossomos, também denominadas "aberrações cromossômicas". As técnicas laboratoriais disponíveis para identificação de mutações cromossômicas e gênicas são diferentes bem como suas conseqüências. $O$ acúmulo de mutações somáticas, por exemplo, pode levar ao câncer, enquanto mutações em células germinativas podem provocar abortos precoces, crianças malformadas ou mesmo portadores assintomáticos de genes potencialmente deletérios ${ }^{1}$.

Atualmente, um grande número de agentes físicos, químicos e biológicos, responsáveis por alterações no material genético, tem sido identificado e descrito na literatura. Entre eles estão ondas eletromagnéticas, fármacos, substâncias que afetam o sistema nervoso central, antibióticos, conservantes alimentares, pesticidas, além de alguns vírus e protozoários ${ }^{2}$.

Entre as substâncias consideradas mutagênicas, existem algumas capazes de alterar a estrutura dos cromossomos, sendo por isso denominadas "clastogênicas", da raiz grega klastos que significa "quebra" ou "fragmento". A avaliação de substâncias clastogênicas somente foi possível a partir do desenvolvimento de técnicas, principalmente citogenéticas, de tecidos humanos. Essas técnicas, que avaliam o efeito mutagênico de uma substância a partir da freqüência de aberrações cromossômicas induzidas, oferecem algumas vantagens, uma vez que podem ser utilizadas diretamente na espécie humana, permitindo a análise de um grande número de células, gerando indicações indiretas de mutações.

Não é difícil associarmos o acúmulo de mutações no DNA como quebras, rearranjos e aneuploidias com risco aumentado de câncer uma vez que a maior parte dos agentes, com comprovada ação carcinogênica, são indutores dessas mutações ${ }^{3}$. Por outro lado, as quebras cromossômicas e os rearranjos cromossômicos, resultantes dessas quebras, observados em linfócitos de sangue periférico de populações expostas, são freqüentemente detectados em células cancerosas.
O câncer é considerado uma doença genética que se manifesta pelo acúmulo de mutações no DNA no decorrer de um espaço de tempo, quase sempre longo. O acúmulo de alterações no material genético da célula depende de vários fatores endógenos como sexo, idade e constituição genética. $E$ depende também de fatores externos como hábitos de consumo, alimentação, uso de medicamentos, exposição a químicos, entre outros. Nesse sentido, as exposições ocupacionais podem atuar como agentes silenciosos na indução de danos no DNA, sendo crescente, por exemplo, o número de processos produtivos que são considerados potencialmente cancerígenos, ou seja, atividades nas quais observase o desenvolvimento, em excesso, de câncer entre os trabalhadores que as exercem ${ }^{4}$. Nestas situações, o trabalhador pode estar exposto a um perfil de misturas complexas de químicos com potencial deletério sobre a sua saúde 5 .

A identificação de danos não perceptíveis (diagnóstico preditivo), com possíveis efeitos num futuro mais distante sobre a qualidade de vida dos indivíduos, será objeto privilegiado de interesse em saúde do trabalhador nas próximas décadas ${ }^{4,6,7}$. 0 estudo de biomarcadores de exposição, também considerados por alguns autores como biomarcadores de efeito precoce, inclui a detecção direta, ao microscópio, de danos no DNA. Diversos testes citogenéticos podem ser aplicados para esse fim, como trocas entre cromátides irmãs (SCE-sister chromatid exchange), teste do Cometa, também conhecido como teste de célula única em gel de agarose (SCGE Single Cell Gel Electrophoresis), teste do micronúcleo (MN) e o teste de aberrações cromossômicas $(C A)^{8}$.

Os testes de mutagenicidade visam identificar aumento na incidência de mutações em populações de risco, comparadas com grupos-controle. As aberrações cromossômicas numéricas e/ou estruturais podem ser visualizadas em cromossomos metafásicos, sendo este teste considerado um indicador extremamente sensível de mutações, tanto in vivo, quanto in vitro ${ }^{9}$. Pesquisas epidemiológicas recentes confirmaram uma maior incidência de câncer em indivíduos que apresentaram, cerca de 15 anos antes do aparecimento da doença, aumento na freqüência de aberrações cromossômicas em linfócitos, indicando haver efeito mutagênico semelhante no tecido alvo ${ }^{10,11}$. Todavia, os autores não conseguiram estabelecer a contribuição efetiva de diferentes hábitos de vida ou mesmo do tipo de ocupação no aumento da freqüência de aberrações cromossômicas e do conseqüente aparecimento de câncer ${ }^{12}$.

Além das exposições ocupacionais, os hábitos de consumo como ingestão de bebidas alcoólicas, 
tabagismo, drogas ilícitas e medicamentos, além da dieta, parecem influir na incidência de aberrações cromossômicas, tanto in vitro quanto in vivo ${ }^{13,14}$. O consumo crônico de bebidas alcoólicas tem sido relacionado a diferentes tipos de câncer e com o aumento, estatisticamente significante, na freqüência de linfócitos com aberrações cromossômicas numéricas e/ou estruturais ${ }^{15}$. Isso ocorre mesmo após longos períodos de abstinência, sugerindo uma ação do álcool na capacidade de reparo celular e nas funções oxidativas da célula ${ }^{16,17}$. Dessa forma, os testes citogenéticos, quando aplicados em populações ocupacionalmente expostas, devem levar em consideração os hábitos de consumo que muitas vezes podem surgir como fatores de confusão na avaliação dos resultados ${ }^{18}$.

Outro teste que vem sendo utilizado no monitoramento biológico de populações humanas, expostas aos agentes mutagênicos e carcinogênicos, é o teste do micronúcleo. Os MNs são identificados em células interfásicas e se apresentam na forma de corpúsculos citoplasmáticos, de tamanho não superior a um terço do núcleo principal. Correspondem a fragmentos acêntricos resultantes de deleções cromossômicas ou cromossomos inteiros que se atrasam durante a anáfase da divisão celular. O teste do MN é considerado, por vários autores, como um teste auxiliar rápido e econômico na análise de aberrações cromossômicas ${ }^{19}$.

Somente células em divisão podem expressar $\mathrm{MN}$, sendo que a freqüência do mesmo depende da cinética celular e do tecido em estudo. Dentre os tipos celulares utilizados para o teste do MN incluem-se os linfócitos de sangue periférico, cultivados in vitro e tratados com citocalasina- $\mathrm{B}$, células epiteliais da mucosa oral, mucosa vaginal, entre outros. A análise de células epiteliais é um método não invasivo que permite coletas sucessivas, além do estudo direto das células da camada basal que sofreram mutação, em média, até 20 dias após a exposição. Desde 1992 temos utilizado o teste do MN no monitoramento de populações ocupacionalmente expostas ${ }^{20,21,22,23,24,25}$, além do monitoramento de populações de risco para o câncer ${ }^{26,27,28,29}$ e no estudo da ação de substâncias como álcool e compostos da maconha, in vitro ${ }^{30}$.

Mais recentemente, o teste do Cometa, que avalia lesões no DNA de células únicas que são passíveis de reparo, tem sido incorporado na avaliação de populações ocupacionalmente expostas ${ }^{31}$. Nesse teste, células individualizadas em uma lâmina de vidro com gel de agarose, são primeiramente lisadas e depois expostas a uma corrente de eletroforese, provocando a migração do DNA para o pólo positivo (ânodo). Como ocorreu a lise das membranas (celular e nuclear) e das histonas, o DNA se expande no espaço formado no gel e, caso tenham ocorrido quebras, as alças de DNA se movimentam formando um halo. Essa imagem na forma de "cometa" é visualizada em microscópio de fluorescência, e as células são classificadas de acordo com o tamanho da cauda e intensidade de fluorescência. A análise pode ser feita qualitativamente ao microscópio ou por programas específicos de análise de imagem.

Nos últimos anos o teste do Cometa foi implantado em nosso laboratório e tem sido utilizado não só na avaliação de populações ocupacionalmente expostas $^{25,32}$ como também na avaliação de substâncias específicas nos testes in vitro ${ }^{33}$.

Embora os testes acima mencionados tenham a capacidade de identificar células com danos no DNA, o significado dessas alterações em termos de risco de câncer ainda está longe de ser estabelecido. Assim sendo, não se pode inferir, até o momento, se os marcadores que avaliam instabilidade cromossômica e aneuploidia possuem o mesmo valor que os testes que identificam inativação do gene p53, um supressor tumoral que atua como guardião de nosso genoma, impedindo o estabelecimento de mutações ${ }^{18}$.

\section{BIOMONITORAMENTO E TRABALHO: MOTORIS- TAS DE ONIBUS URBANOS}

Desde a Antigüidade, há registros da relação entre trabalho e saúde-doença. Historiadores da medicina, como Henry Sigerist e George Rosen, mostram em seus estudos que é possível detectar alguma referência sobre a associação entre o trabalho e a saúde-doença, ainda que escassa, já desde os papiros egípcios. Importantes observações no reconhecimento das relações do trabalho e saúde-doença foram feitas por Hipócrates, que reconheceu riscos ocupacionais específicos e ligou doenças particulares a ocupações ${ }^{34}$.

Atualmente, a Saúde do Trabalhador é um campo em construção no espaço da saúde pública. Assim, sua descrição constitui, antes, uma tentativa de aproximação de um objeto e de uma prática, com vistas a contribuir para sua consolidação enquanto área ${ }^{35}$.

Estudos de biomonitoramento em populações humanas, expostas ambiental e/ou ocupacionalmente a altos níveis de misturas complexas de poluentes aéreos urbanos demonstram um risco genotóxico em humanos com a formação de adutos de DNA e conseqüentemente, incidência aumentada de danos cromossômicos $^{36,37,38}$.

O ar urbano contém uma diversidade de compostos químicos, alguns dos quais são genotóxicos. A fonte mais importante de genotoxinas na poluição aérea é a combustão incompleta de 
Kohatsu AGS et al. Utilização dos testes de mutagenicidade para a avaliação de exposição ocupacional.

combustíveis fósseis (automóveis, aquecimento de residências e emissões industriais). A composição da combustão de automóveis é complexa e geralmente contém monóxido de carbono, óxidos de nitrogênio, particulados e hidrocarbonetos especialmente os hidrocarbonetos policíclicos aromáticos (HPAs), nitroaromáticos, benzeno, 1,3 butadieno, dióxido de enxofre e chumbo ${ }^{39}$.

Estudo epidemiológico demonstrou que pessoas moradoras de áreas urbanas possuem um risco aumentado de câncer de pulmão quando comparadas às que moram fora das áreas metropolitanas ${ }^{40}$. Um risco aumentado de câncer de pulmão e do trato gastrointestinal também foi relatado por Guberan et al. ${ }^{41}$, em ocupações com exposição pesada a poluentes de tráfego.

Dentre as ocupações com possíveis riscos à saúde inclui-se a de motoristas de ônibus, pois estes profissionais frequentemente relatam dores nas costas, doenças pulmonares, alergias e hipertensão, entre outras. Especialmente sujeitos às complicações de saúde estão os motoristas de grandes cidades como São Paulo, diariamente expostos à poluição, principalmente compostos químicos resultantes da emissão de veículos automotivos. Entre esses compostos está o benzeno, substância capaz de formar adutos e danos no material genético, aumentando o risco de desenvolvimento de câncer ${ }^{36,38}$.

Burgaz et al. ${ }^{37}$ avaliaram os efeitos mutagênicos da poluição urbana aérea, analisando a freqüência de aberrações cromossômicas (AC) em linfócitos de sangue periférico de motoristas de táxi e policiais de tráfego em Ankara na Turquia. Os autores também estimaram a exposição aos hidrocarbonetos policíclicos aromáticos (HPAs) medindo-se os níveis de 1-hidroxipireno (1-OHP) na urina desses profissionais. A freqüência de $A C$ foi maior no grupo exposto $(1.3 \pm 1.6$ policiais de tráfego/ $1.8 \pm 1.7$ motoristas de táxi) quando comparado ao grupo controle $(0,2 \pm 0,7)$ e essa diferença foi considerada estatisticamente significante $(p<0.05 ; p<0.01)$.

Em outro estudo realizado na mesma época em Roma, também foram avaliados trabalhadores expostos à poluição aérea ${ }^{42}$. Nesse trabalho, além da freqüência de danos cromossômicos em linfócitos pelo teste do cometa os autores compararam a susceptibilidade individual a uma maior freqüência de danos, bem como de risco de câncer, avaliando a freqüência de polimorfismos nos genes de metabolização de xenobióticos (CYP1A1, CYP2E1, NQ01, GSTM1, GSTT1). No caso do ensaio do cometa, a diferença entre os grupos estudados não foi estatisticamente significante, o que foi atribuído aos efeitos da exposição aos poluentes aéreos que não foram suficientes para induzir danos cromossômicos detectáveis.

O teste do micronúcleo foi o teste escolhido para biomonitorar um grupo de trabalhadores potencialmente expostos a fumaças de tráfego no Reino Unido ${ }^{43}$. No entanto não foi encontrado resultado estatisticamente significante.

Posteriormente, Maffei et al. ${ }^{44}$ também utilizaram o teste do MN para avaliar os efeitos ambientais do benzeno em policiais que trabalhavam em áreas urbanas na cidade de Bologna, Itália. Neste estudo, o aumento na freqüência de $\mathrm{MN}$ foi significativo $(P=0.001)$ quando comparados, casos $(7.06 \pm 2.87)$ versus controles $(4.83 \pm 1.84)$. Outro estudo realizado em Bologna, que comparou a exposição ao benzeno e a indução de micronúcleos em trabalhadores de laboratórios químicos e em trabalhadores de trânsito, mostrou uma freqüência similar de $\mathrm{MN}$ nos dois grupos quando comparados um ao outro ${ }^{45}$.

Aparentemente, em um único trabalho realizado em Ankara na Turquia, avaliou-se a freqüência de MN em células da mucosa oral de três diferentes grupos de trabalhadores, expostos aos HPAs (mecânicos de motor, motoristas de táxi e policiais de trânsito). Esses grupos foram comparados a dois diferentes grupos controle. Neste estudo, apesar dos grupos expostos terem uma freqüência de $\mathrm{MN}$ maior que os grupos controle, tal freqüência não foi estatisticamente significante $^{46}$.

Devido ao conhecimento das condições de trabalho e das condições do ar atmosférico da cidade de São Paulo, com altos índices de poluição, foi realizada pelo Serviço de Saúde Ocupacional do HCFMUSP e pelo Laboratório de Imunohematologia e Hematologia Forense do Departamento de Medicina Legal, Ética Médica e Medicina Social e do Trabalho da FMUSP (LIM/40), uma avaliação das condições de saúde de motoristas de ônibus urbanos da cidade de São Paulo.

$\mathrm{Na}$ presente investigação foi investigada a freqüência de danos citogenéticos em motoristas de ônibus da cidade de São Paulo, por meio do teste do micronúcleo, em células da mucosa oral. Além da coleta de material biológico, foi investigada a história profissional e os hábitos de vida destes indivíduos.

Foram avaliados 24 motoristas de ônibus com idades entre 26 e 63 anos (média 44,2 + 10,2 anos), que estavam exercendo a profissão há pelo menos

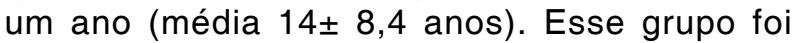
comparado com 13 motoristas de ônibus que estavam afastados de suas funções há pelo menos seis meses, sendo que o grupo aqui denominado "controle" também exercia a mesma ocupação.

A análise citogenética foi realizada em 24.000 células de 24 motoristas de ônibus ativos e em 13.000 células de 13 motoristas afastados. O número de 
células com MN observadas nos casos variou de zero a cinco (23/24.000 células) e nos controles de zero a duas células com micronúcleo (6/13.000), tendo sido esta diferença não significante $\left(?^{2}=2,6\right.$; IC de $95 \%$ : $0,8-5,1 ; p=0,1)$.

Os resultados de biomonitoramento de populações expostas devem levar em consideração fatores individuais como consumo de álcool e tabaco. Verificou-se que entre os motoristas muitos (75\%) faziam uso de bebidas alcoólicas ao menos uma vez na semana, sendo que entre os controles, este número foi menor (23\%). Em relação ao cigarro, também havia mais fumantes entre os casos (25\%) do que nos controles $(7,7 \%)$. Entretanto, na presente análise os dados relacionados ao consumo de álcool e cigarro, não foram comparados com os resultados citogenéticos. Nesse tipo de investigação a seleção das amostras populacionais a serem estudadas, bem como a identificação de outros fatores de risco como hábitos (fumo, álcool, drogas, medicamentos, etc.) ou mesmo tempo de exposição devem ser, criteriosamente avaliados, em um número significante de indivíduos (Protocolo adaptado ${ }^{19}$ ).

Os resultados obtidos nesta investigação indicam um risco maior de danos no material genético em motoristas na ativa do que naqueles afastados de suas funções. Apesar disso, devem ser analisados com cautela em decorrência principalmente do número de indivíduos pesquisados e da seleção dos controles.

Os resultados parciais dessa pesquisa, realizada com pacientes em atendimento no Serviço de Saúde Ocupacional do HCFMUSP, sugerem a ampliação desse projeto e possivelmente a inclusão de protocolos de avaliação periódica desses profissionais, uma vez que os mesmos estão expostos de forma intermitente aos poluentes urbanos na cidade de São Paulo.

Kohatsu AGS, Shimabukuro F, Gattás GJF. Use of mutagenicity tests to assess occupational exposure. Saúde, Ética \& Justiça. 2007;12(1/2):15-21.

ABSTRACT: The cytogenetic tests are important biomarkers of exposure to evaluate mutagenic effects of external agents and its metabolites in the internal cell environment. These tests have been used in the biological monitoring of populations exposed to genotoxic substances, mainly in the occupational area. The frequency micronucleous, evaluated in 24 bus drivers of the city of São Paulo, was higher than the frequency observed in a control group of 13 bus drivers who were away from their jobs for more than six months. In spite of the low number of individuals, the partial results of this research that was performed with patients who attended the Occupational Health Service of the HCFMUSP, suggest an expansion of this project to evaluate a possible inclusion of periodic tests protocol for these professionals in the future.

KEY WORDS: Cytogenetics. Mutagenicity tests. Micronucleus tests. Occupational exposure. Occupational health, bus driver.

\section{REFERÊNCIAS}

1. Hartl DL, Jones EW. Mutation, DNA repair, and recombination. In: Hartl DL, Jones EW, editors. Genetics. Principles and analysis. Canada: Jones and Bartlett Publishers; 1998. p.554-97.

2. Wogan GN, Hecht SS, Felton JS, Conney AH, Loeb LA. Environmental and chemical carcinogenesis. Semin Cancer Biol. 2004;14(6):473-86.

3. Waters MD, Stack HF, Jackson MA. Genetic toxicology data in the evaluation of potential human environmental carcinogens. Mutat Res. 1999;437:2149.

4. Gattás GJF. Biomarcadores moleculares. In: Tratado de clínica médica. São Paulo: Roca; 2006. p. 210-6.

5. Clapp RW, Howe GK, Jacobs M. Environmental and occupational causes of cancer re-visited. J Public Health Policy. 2006;27(1):61-76.

6. Gattás GJF, Segre M, Wünsch Filho V. Genética, biologia molecular e ética: as relações trabalho e saúde. Ciên Saúde Coletiva. 2002;7:159-67.

7. Rischitelli DG, Berman F, McCauley LA. Occupational and environmental health in the 21st century: the new frontier in genetics and disease prevention. AAOHN J. 2005;53(12):522-8.

8. Au WW, Lee E, Christiani DC. Biomarker research in occupational health. J Occup Environ Med. 2005;47(2):145-53.

9. Hagmar L, Stromberg U, Tinnerberg H, Mikoczy Z. The usefulness of cytogenetic biomarkers as intermediate endpoints in carcinogenesis. Int J Hyg Environ Health. 2001;204(1):43-7.

10. Bonassi S, Znaor A, Norppa H, Hagmar L. Chromosomal aberrations and risk of cancer in humans: an epidemiologic perspective. Cytogenet Genome Res. 2004;104(1-4):376-82. 
Kohatsu AGS et al. Utilização dos testes de mutagenicidade para a avaliação de exposição ocupacional.

11. Rossner P, Boffetta P, Ceppi M, Bonassi S, Smerhovsky Z, Landa K, et al. Chromosomal aberrations in lymphocytes of healthy subjects and risk of cancer. Environ Health Perspect. 2005;113(5):517-20.

12. Bonassi S, Hagmar L, Stromberg U, Montagud AH, Tinnerberg $\mathrm{H}$, Forni $\mathrm{S}$, et al. Chromosomal aberrations in lymphocytes predict human cancer independently of exposure to carcinogens. European Study Group on Cytogenetic Biomarkers and Health. Cancer Res. 2000;60(6):1619-25.

13. Gattás GJF, Wajntal A, Saldanha PH. In vitro cytogenetic effects of cannabidiol on human lymphocyte cultures. Rev Bras Genet. 1989;12(3):613-23.

14. Barale R, Chelotti L, Davini T, Delry S, Andreassi $M G$, Ballardin $M$, et al. Sister chromatid exchange and micronucleus frequency in human lymphocytes of 1,650 subjects in an Italian population: II. Contribution of sex, age and lifestyle. Environ. Mol. Mutagen. 1998;31: 228-242.

15. Maffei F, Forti GC, Castelli E, Stefanini GF, Mattioli S, Hrelia P. Biomarkers to assess the genetic damage induced by alcohol abuse in human lymphocytes. Mutat Res. 2002;15;514(1-2):49-58.

16. Gattás GJ, Saldanha PH. Chromosomal aberrations in peripheral lymphocytes of abstinent alcoholics. Alcohol Clin Exp Res. 1997;21(2):238-43.

17. Burim RV, Canalle R, Takahashi CS, Tavares DC, Martinelli A de L, Sakamoto-Hojo ET. Clastogenic effect of ethanol in chronic and abstinent alcoholics. Mutat Res. 2004;560(2):187-98.

18. Bonassi S, Ugolini D, Kirsch-Volders M, Stromberg $\mathrm{U}$, Vermeulen R, Tucker JD. Human population studies with cytogenetic biomarkers: review of the literature and future prospectives. Environ $\mathrm{Mol}$ Mutagen. 2005;45(2-3):258-70.

19. Fenech M, Holland N, Chang WP, Zeiger E, Bonassi S. The Human Micronucleus Project - An international collaborative study on the use of the micronucleus technique for measuring DNA damage in humans. Mutat Res. 1999;428:271-83.

20. Soares-Vieira JA, Cardoso LA, Macário RCRE, Gattás GJF, Côrrea GM, Zaher VL. Avaliação mutagênica de profissionais da saúde expostos ao mercúrio pela análise de micronúcleos (MN). Rev Bras Genet. 1995;18(suppl 3):368.

21. Döppenschimitt E, Zaher VL, Pereira CAB, Gattás GJF. Micronucleus in civil architecture employees: can they be useful as a control in mutagenic tests? In: Resumenes ALAMCTA; 1996. p.89.

22. Gattás GJ, Cardoso L de A, Medrado-Faria M de A, Saldanha PH. Frequency of oral mucosa micronuclei in gas station operators after introducing methanol. Occup Med (Lond). 2001;51(2):107-13.

23. Kato M, Loomis D, Demarini D, Brooks L, Gomes L, Carvalho $A B$, et al. Occupational risks of charcoal production in Bahia State, Brazil. In: XVI EPICOH;
Barcelona, Espanha; 2002 Sept. 11-14. Abstract ID:031.

24. Salman FC, Carvalho DF. Estudo de mutagenicidade em anestesiologistas do sexo feminino [monografia conclusão de curso - Medicina do Trabalho]. São Paulo: Departamento de Medicina Legal, Ética Médica e Medicina Social e do Trabalho, Faculdade de Medicina, Universidade de São Paulo; 2003.

25. Galiotte MP. Avaliação de mutagenicidade em profissionais de institutos de beleza por meio de testes citogenéticos [dissertação]. São Paulo: Faculdade de Medicina, Universidade de São Paulo; 2006.

26. Gattás GJF, Longatto Filho A, Maeda MYS, Santos $\mathrm{DR}$, De Andrea Filho A. Identificação de micronúcleos (MN) em células de colo uterino de pacientes assintomáticos: correlação dos métodos de Papanicolaou e Fuelgen Fast-green. Folha Med. 1992;104(3):57-9.

27. Ramirez A, Gattás GJF, Carvalho MB, Rappoport A, Saldanha $\mathrm{PH}$. Micronuclei frequency in patients with oral carcinomas. Environ Mol Mutagen. 1998;31(Suppl 29):75.

28. Gomes L, Mello ES, Vezozzo DCP, Carrilho FJ, Alves VAF, Gattás GJF. Avaliação da frequência de micronúcleos ( $\mathrm{MN}$ ) em células hepáticas normais e fígados cirróticos explantados. Genet Mol Biol. 1999;22(supl. 3):785.

29. Carvalho MB, Ramirez A, Gattás GJF, Guedes AL, Amar A, Rapoport A, et al. Correlação entre a evolução clínica e a freqüência de micronúcleos em células de pacientes portadores de carcinomas orais e da orofaringe. Rev Assoc Med Bras. 2002;48(4):31722.

30. Gomes L, Gattás GJF. In vitro mutagenic evaluation of cannabidiol (CBD), a marihuana compound, on human lymphocytes by the micronucleus and comet assay tests. Environ Mol Mutagen. 2001;37(Suppl 32):35.

31. Moller P, Knudsen LE, Loft, S. Wallin H. The comet assay as a rapid test in biomonitoring occupational exposure to DNA-damaging agents and effect of confounding factors. Cancer Epidemiol Biomarkers Prev. 2000;9(10):1005-15.

32. Gomes L, Kato M, Gattás GJF, Rego MAV. DNA single strand breaks in nasal mucous cells, and leukocytes of charcoal workers in Brazil. Environ Mol Mutagen. 2002;39(Suppl 33):29.

33. Gomes L, Gattás GJF. In vitro mutagenic evaluation of cannabidiol (CBD), a marihuana compound, on human lymphocytes by the micronucleus and comet assay tests. Environ Mol Mutagen. 2001;37(Suppl 32):35.

34. Mendes R, Waissmann W. Aspectos históricos da patologia do trabalho. In: Mendes R, Patologia do trabalho. São Paulo: Atheneu; 2003. p.4-39.

35. Mendes R, Dias EC. Da Medicina do trabalho à saúde do trabalhador. Rev Saude Publ. 1991;25: 341-9. 
36. Bodell WJ, Levay G, Pongracz K. Investigation of benzene-DNA adducts and their detection in human bone marrow. Environ Health Perspect. 1993;99:241-4.

37. Burgaz S, Demircigil GC, Karahalil B, Karakaya AE. Chromosomal damage in peripheral blood lymphocytes of traffic policemen and taxi drivers exposed to urban air pollution. Chemosphere. 2002;47:57-64.

38. Gaskell M, McLuckie KI, Farmer PB. Comparison of the mutagenic activity of the benzene metabolites, hydroquinone and para-benzoquinone in the supF forward mutation assay: a role for minor DNA adducts formed from hydroquinone in benzene mutagenicity. Mutat Res. 2004;554(1-2):387-98.

39. IARC, International Agency for Research on Cancer. Diesel and gasoline engine exhaust and some nitroarenes. Lyon: IARC, 1989. p.41. (IARC Monographs on the evaluation of carcinogenic risks to humans, n.46).

40. Hemminki K, Pershagen G. Cancer risk of air pollution: epidemiological evidence. Environ Health Perspect. 1994;102:187-92.

41. Guberan E, Usel M, Raymond L, Bolay J, Fioretta $G$, Puissant J. Increased risk for lung cancer and cancer of the gastrointestinal tract among Geneva professional drivers. Br J Ind Med. 1992;49:33744.

42. Carere A, Andreoli C, Galati R, Leopardi $P$, Marcon $F$, Rosati MV, et al. Biomonitoring of exposure to urban air pollutants: analysis of sister chromatid exchanges and DNA lesions in peripheral lymphocytes of traffic policemen. Mutat Res. 2002;518:215-24.

43. Parry EM, Ballantine JA, Ellard S, Evans WE, Jones $\mathrm{C}$, Kilic $\mathrm{N}$, et al. Biomonitoring Study of workers potentially exposed to traffic fumes. Environ Mol Mutagen. 1997;30:119-30.

44. Maffei F, Hrelia P, Angelini S, Carbone F, Forti GC, Barbieri $A$, et al. Effects of environmental benzene: Micronucleus frequencies and haematological values in traffic police working in an urban area. Mutat Res. 2005;583:1-11.

45. Violante FS, Sanguinetti G, Barbieri A, Accorsi A, Matiolli S, Cesari R, et al. Lack of correlation between environmental or biological indicators of benzene exposure at parts per billion levels and micronuclei induction. Environ Res. 2003;91:135-42.

46. Karahalil B, Karakaya AE, Burgaz S. The micronucleus assay in exfoliated buccal cells: application to occupational exposure to polycyclic aromatic hydrocarbons. Mutat Res. 1999;442:29-35. 